\title{
Osteoconductive potential of mesoporous titania implant surfaces loaded with magnesium: an experimental study in the rabbit
}

Silvia Galli ${ }^{\dagger * D D S}$, Yoshihito Naito ${ }^{\ddagger}$ DDS PhD, Johan Karlsson ${ }^{\S} \mathrm{MS}$, Wenxiao He ${ }^{\S} \mathrm{MS}$, Martin Andersson ${ }^{\S} \mathrm{MS} \mathrm{PhD}$, Ann Wennerberg ${ }^{\dagger} \mathrm{DDS} \mathrm{PhD}$, Ryo Jimbo ${ }^{\dagger} \mathrm{DDS}$ PhD.

${ }^{\dagger}$ Department of Prosthodontics, Faculty of Odontology, Malmö University, 20506 Malmö, Sweden;

${ }^{9}$ Department of Oral and Maxillofacial Prosthodontics and Oral Implantology, Institute of Health Biosciences, The University of Tokushima Graduate School, Tokushima, Japan;

${ }^{\S}$ Department of Chemical and Biological Engineering, Applied Surface Chemistry, Chalmers University of Technology, 41296 Gothenburg, Sweden

\section{Corresponding author:}

Silvia Galli,

Department of Prosthodontics, Faculty of Odontology, Malmö University, 20506 Malmö, Sweden. telephone: $+46(0) 406658514$

email: silvia.galli@mah.se,

\section{Author Contributions}

SG: concept/design, animal operations; YN: histological preparation and analysis; JK, WH and MA: material preparation, concept/design; AW and RJ: study design, data analysis.

The manuscript was written through contributions of all authors. All authors have critically revised the manuscript and given approval to the final version of the manuscript. 
ABSTRACT (150-200 words, structured):

Background: Mesoporous coatings enable incorporation of functional substances and sustainably release them at the implant site. A bioactive substance that can be incorporated in mesoporous is magnesium, which is strongly involved in bone metabolism and in osteoblasts interaction.

Purpose: The aim of this experimental study was to evaluate the effect of magnesium-incorporation into mesoporous coatings of oral implants on early stages of osseointegration.

Material and methods: Titanium implants were coated with thin films of mesoporous $\mathrm{TiO}_{2}$ having pore diameters of $6 \mathrm{~nm}$ and were loaded with magnesium. The implant surfaces were extensively characterised by means of interferometry, atomic force microscopy, scanning electron microscopy, energy dispersive spectroscopy, and then placed in the tibiae of 10 rabbits. After 3 weeks of healing, osseointegration was evaluated by means of removal torque test and histology and histomorphometry.

Results: Histological and biomechanical analyses revealed no side effects and a successful osseointegration of the implants. The biomechanical evaluation evidenced a significant effect of magnesium-doping in strengthening the implant-bone interface.

Conclusions: A local release of magnesium from the implant surfaces enhances the implant retention at the early stage of the healing ( 3 weeks), which is highly desirable for early loading of the implant.

KEYWORDS nanoporosity- magnesium - osseointegration - mesoporous titania - titanium implants - local drug delivery 


\section{INTRODUCTION}

Immediately after the implantation of an implant into bone a series of critical events occur. Especially crucial for the new bone formation and the osseointegration of titanium implants is the recruitment of osteogenic cells and their migration, differentiation and adhesion to the surface of the biomaterial $^{1}$.

Osteogenic cells sensitively respond to the topographical, chemical and physical nature of the implant surface ${ }^{2,3}$, and certain surface properties have been suggested to modulate the outcome of osseointegration ${ }^{4}$. Recent studies further suggest that the formation of a biologically inspired implant surface imparts bioactivity ${ }^{5}$, which has the possibility to accelerate osseointegration and strengthen the bone mineralization properties ${ }^{6,7}$.

It has been suggested that the homogenous distribution of nanostructures on an implant surface is one of the key factors to enhance the bioactivity ${ }^{8}$, since cells, proteins and several other entities interact at the nano-level ${ }^{9}$. Since the modification of biomaterial surfaces at the nanoscale would in general modify not only the topography, but also the chemistry and other physical properties ${ }^{10}$, it is thought that the biologic responses obtained with such modifications are the result of synergistic effects ${ }^{11}$.

Previously, we have developed an interesting implant surface modification that has maintained the chemistry but altered the nanotopography, namely the mesoporous coated surface ${ }^{12}$. The mesoporous coating is a thin film of titanium oxide with homogenously distributed nano-pores, which fully cover the base titanium substrate. An interesting feature of this mesoporous surface is that it has the potential to adsorb a higher amount of inorganic ions, and to this followed an increased apatite formation in simulated body fluids compared to its nonporous counterpart ${ }^{12}$. In a study by Harmankaya et al. ${ }^{13}$, the mesoporous titanium coated surface was loaded with different drugs and showed that the surface can indeed function as a drug carrier matrix and accelerate osseointegration ${ }^{13}$. Thus, it can be suggested that the unique nanoporous film has a possibility to be utilized as a host for drugs, proteins, or other chemical substances. 
Different surface chemistry modifications have been proposed and investigated, incorporating different chemical substances such as calcium, phosphate, magnesium, or fluoride using different techniques ${ }^{14-17}$. Among the different elements, the effect of calcium phosphate has been extensively studied and has shown significant biologic responses ${ }^{18-21}$. Furthermore, it has been suggested that the addition of magnesium to the calcium-containing surface improves the biomechanical bonding to the surface ${ }^{22,23}$.

Magnesium $(\mathrm{Mg})$ is one of the most important elements in the human body and it is involved in the regulation of numerous biochemical reactions in cells and tissues. For instance, the biological activation of ATP (adenosine triphosphate) depends on Mg binding and the nucleic acid function is modulated by $\mathrm{Mg}$ ions ${ }^{24}$. In absence of extra-cellular $\mathrm{Mg}$, osteoblast proliferation and metabolism is impaired because $\mathrm{Mg}$ acts as a mitogen factor for cells ${ }^{25}$. Osteoblast-like cell proliferation is significantly reduced concomitantly with the reduction of extracellular $\mathrm{Mg}^{2+}$ in cell cultures $^{26}$ as well as the stimulatory effect of PDGF (platelet-derived growth factor) on cell growth is suppressed ${ }^{27}$. When extracellular Mg-concentrations are too low, an up-regulation of nitric oxide synthase takes place, and subsequent increases of nitric oxide is observed ${ }^{25}$ with possible stimulation of osteoclast activity. Conversely, the degree of viable cell coverage on surfaces in presence of $\mathrm{Mg}$ ions was found higher, with the increase of $\mathrm{Mg}$ doses, although excessively high concentration of $\mathrm{Mg}$ was detrimental for cells as well, possibly due to the alkalinity ${ }^{28}$. Magnesiumdeficiency has been correlated to impaired bone growth, skeletal fragility and osteoporosis in rats, probably for an uncoupling of bone proliferation and bone resorption ${ }^{29,30}$. In addition, the mineral metabolism and the calcification in bone are influenced by $\mathrm{Mg}$ ions ${ }^{31}$, which are known to bind at active growth sites during hydroxyapatite crystallization and to hinder the formation of excessively big and perfect crystal that make the bone brittle ${ }^{32}$. Results from in vitro studies have demonstrated higher cell-adhesion on Mg-surfaces, due to an integrin-mediated mechanism ${ }^{33-35}$ and in vivo studies have shown that $\mathrm{Mg}$ incorporated implants enhance the mineralization of the newly formed bone ${ }^{36,37}$. 
In the present study, magnesium was chosen as the chemical element to incorporate into the mesoporous $\mathrm{TiO}_{2}$ surface. The loading of $\mathrm{Mg}$ was performed by means of physical adsorption. It was hypothesized that the $\mathrm{Mg}$-release from the mesoporous $\mathrm{TiO}_{2}$ implants would significantly promote the initial osteoconduction and the interfacial bonding strength of the implants to the bone. Thus, the implants were inserted in the rabbit tibiae and the effect of $\mathrm{Mg}$ incorporation was evaluated biomechanically and histologically after 3 weeks in vivo. The period 3 weeks post implantation in the rabbit model has been used in past studies as to observe relatively early bone healing ${ }^{38} \cdot{ }^{39}$ Therefore this time frame was chosen to test the hypothesis that the initial release of $\mathrm{Mg}$ from the nanostructured surface would influence the surface osteoconductivity and the early phenomena of new bone formation.

\section{MATERIAL AND METHODS}

Material preparation:

Forty commercially available threaded titanium implants (Neodent, Curitiba, Brasil) with a diameter of $3.5 \mathrm{~mm}$ and a length of $7 \mathrm{~mm}$ have been used for this study. All the implants had originally turned surfaces. Mesoporous $\mathrm{TiO}_{2}$ coating were formed on the implant surfaces using the evaporation induced self-assembly (EISA) method, as previously described ${ }^{12}$. In brief, the Pluronic P123 solution (a triblock copolymer of ethylene glycol 20 -propylen glycol $_{70}$ - ethylene glycol $_{20}$ ), used as a template, was dissolved in ethanol $(99.5 \%)$ and then stirred vigorously for $1 \mathrm{~h}$. In a separate vial, another solution containing titanium (IV) tetraethoxide, the inorganic precursor, was mixed and stirred with concentrated hydrochloric acid. The two solutions, with concentrations to obtain a cubic mesoporous structure ${ }^{40}$ were then mixed together. The solution was deposited onto titanium implants, a homogenous film was then formed by spin-coating for $1 \mathrm{~min}$ at $7500 \mathrm{rpm}$. The coated implants were kept in room temperature overnight to complete the self-assembly process of the template and to further evaporate solvents. The dried thin films were calcinated for $4 \mathrm{~h}$ at $350^{\circ} \mathrm{C}$ in 
order to remove the template and increase the cross-linking density of the titania through condensation.

Thereafter, a solution of magnesium-chloride dissolved in Milli Q water (1:99) was prepared and half of the samples were soaked in it for an hour. The liquid in excess was then removed by nitrogen gas and the samples were put in a vacuum oven at $100^{\circ} \mathrm{C}$ for half an hour.

The rest of the implants, without $\mathrm{Mg}$ loading, were used as controls. Twenty-eight of the implants prepared were implanted, while 12 were used for material characterization.

The same procedure was used to apply the mesoporous coating to 6 titanium discs, half of which were loaded with the magnesium-chloride solution.

Material characterization:

Characterization of topography, morphology and chemical composition of the surfaces was performed.

\section{Interferometry:}

Surface roughness was investigated with white light optical interferometry, whose principles is described elsewhere ${ }^{41}$. A MicroXAM (ADE Phase shift technology, Inc., Arizona, USA) was used for this experiment and it was set with a $50 \mathrm{X}$ objective, a zoom factor of 0.625 , a vertical range of measurement of $100 \mu \mathrm{m}$ and a standard scanning area of $264 \times 200 \mu \mathrm{m}$. The area of measurement was eventually adjusted to fit the surface shape. Three implants per group were measured and the sampling took place in random areas of 3 tops, 3 valleys and 3 flanks of each implant.

To filter out the waviness and the form from the actual roughness, a Gaussian filter with a size 50 X $50 \mu \mathrm{m}$ was applied, as suggested in the guidelines from Wennerberg and Albrektsson ${ }^{41}$. The numerical description of the surface topography was obtained through the software Surface Scan (Somitronic Instrument, Lyon, France) and 4 parameters were chosen $\left(S_{\mathrm{a}}, \mathrm{S}_{\mathrm{dr}}, \mathrm{S}_{\mathrm{ds}}, \mathrm{S}_{\mathrm{sk}}\right)$. 
Visual figures of the surfaces were obtained with Mountain Map software (Digital Surf, France) and were used for qualitative evaluation.

\section{Atomic Force Microscopy}

Atomic force microscopy (XE-100, Park System, Suwon, Korea) was used to evaluate the coated discs at the nanometer level. Three discs per coating type were selected for the analysis and 3 randomly chosen regions were measured on each. The microscope operated at a tapping mode in air and at room temperature and 3 scan areas were acquired for each region $\left(10 \times 10 \mu \mathrm{m}^{2}, 1 \times 1 \mu \mathrm{m}^{2}\right.$ and $500 \mathrm{X} 500 \mathrm{~nm}^{2}$ ). Imaging and parametric calculation were performed after the removal of form and waviness by Gaussian filtering $\left(2.5 \times 2.5 \mu \mathrm{m}^{2}, 0.25 \times 0.25 \mu \mathrm{m}^{2}\right.$ and $125 \times 125 \mathrm{~nm}$, respectively for the 3 different scan areas) with the Mountain Map software (Digital Surf, France). The same parameters used for interferometer analysis $\left(\mathrm{S}_{\mathrm{a}}, \mathrm{S}_{\mathrm{dr}}, \mathrm{S}_{\mathrm{ds}}\right)$, were evaluated.

\section{Scanning electron microscopy (SEM)}

Scanning electron microscopy was used to visualize the surface morphology in terms of porosity and coating thickness of the mesoporous matrix. A Leo Ultra55 FEG Instrument (Zeiss, Oberkochen, Germany) was used with an accelerating voltage of $5 \mathrm{kV}$. An in-lens secondary electron detector was utilized for visualization of the pores and the coating thickness. Micrographs were taken at different areas of the implant surfaces, randomly chosen, and again the measurements were run on 3 samples per group. Different magnifications were applied (ranging from $70 \mathrm{X}$ to $200,000 \mathrm{X})$.

\section{Energy dispersive spectroscopy (EDS)}

The implants were analyzed chemically utilizing electron dispersive spectroscopy (EDS). The acceleration voltage of the electron beam used was set to $12 \mathrm{kV}$ and it was directed to 
randomly chosen areas of the implant surfaces. The emitted spectra was detected and analyzed by the Oxford Inca EDS system (Oxford, Inc., Oxfordshire, United Kingdom).

\section{Animals and surgical procedures:}

The animal trial was conducted under the approval from the ethical committee for animal experiments at the Ecole Nationelle Veterinaire D'Alfort, Masion D’Alfort, France. Adequate procedures were conducted to minimize the animal pain or discomfort.

Ten female New Zealand White (NZW) rabbits weighting between 3 and $3.6 \mathrm{~kg}$ were used for this study.

General anesthesia was inducted in the animals by intramuscular injection of $250 \mu \mathrm{m} / \mathrm{kg}$ of medetomidine (Domitor, Zoetis, France) + 20 mg/kg de ketamine (Imalgène 1000, Merial, Sanofi, France) $+1 \mathrm{mg} / \mathrm{kg}$ of diazepam (Valium, Roche, France). Intramuscolar injection $0.2 \mathrm{mg} / \mathrm{kg}$ of méloxicam (Metacam, Boehringer Ingelheim Vetmedica, Inc., United States) and subcutaneous injection of $30 \mu \mathrm{g} / \mathrm{kg}$ of buprénorphine (Buprécare, Animalcare, UK) followed.

Constant perfusion of $\mathrm{NaCl} 0.9 \%$ was performed through venous way during the whole intervention. The rabbits were kept in spontaneous ventilation of $100 \%$ of $\mathrm{O}_{2}$ and gaseous isofluorane $0.5 \%$ were added if necessary.

In the tibia of each rabbit a longitudinal incision was made, a full-thickness flap was elevated and the bone was exposed. A sequence of round burs, with diameter from 2 to $3.15 \mathrm{~mm}$, was used at a drilling speed of $1200 \mathrm{rpm}$ to prepare the implant bed. Countersinking was performed with a final drill of $3.5 \mathrm{~mm}$. One implant of the test or of the control group was inserted in each tibia, engaging only the upper cortical bone. In 4 animals, 2 implants of the same group have been placed in each tibia. Primary wound closure was obtained with a resorbable suture (Vycril 3.0). Each rabbit received the test implants in one leg and the controls in the other, with a randomized allocation of the sample type. 
After the surgery, a patch of fentanyl (Duragesic, Janssen Pharmaceutica, Beerse, Belgium ) has been attached to the shaved neck of the animals and was let to diffuse for 3 days. Antibiotic (enrofloxacine, 200mg/l, Baytril, Bayer Animal Health, Germany) was dissolved in the water of the animals for 5 days. Analgesia with meloxicam (Metacam, Boehringer Ingelheim Vetmedica, Inc., United States), after 48 hours from the intervention and protracted for 5 days. The rabbits were kept in separate cages and fed ad libidum.

After 3 weeks of healing the rabbits were sacrificed with a lethal injection of sodium pentobarbital (Euthasol, Virbac, Fort Worth, USA).

The animal legs were dissected and removal torque test was performed with a manual torque wrench (Tohnichi, Japan). The calibrated instrument was connected to the implant, which was unscrewed until interfacial failure. The instrument displayed the peak resistance to the rotational force in $\mathrm{Ncm}$ and that value was assigned as removal torque value of the implant, the moment of force needed to loosen the implants from the bone.

\section{Histological analysis:}

In order to examine the new bone formation around the implants, 4 implants per type were retrieved with the surrounding bone and they were processed for histological analyses. The retrieved bone blocks were placed in ethanol $70 \%$ for transportation in the laboratory, where they underwent fixation and dehydration. Subsequently, the samples were infiltrated with 2hydroxyethyl methacrylate light-curing resin (Technovit 7200 VLC; Heraeus Kulzer Wehrheim, Germany) and finally embedded in the same resin.

Non-decalcified sections were then cut with the Exakt saw (Exakt Apparatebau, Norderstedt, Germany) parallel to the long axis of the implant and grinded down to a thickness between 30 and $10 \mu \mathrm{m}$ following the cutting-grinding technique ${ }^{42}$. The sections were stained with Toluidine blue-pyronin dye and then observed at light microscopy (Eclipse ME600; Nikon, Tokyo, 
Japan). Histomorphometric measurements were performed using the Image $\mathbf{J}$ software (NIH, USA) for image analyses at magnification of 40X. The parameters observed were:

1) Bone-to-implant contact (BIC, \%): percentage of implant surface in direct contact with the bone matrix, measured in the three best consecutive threads;

2) Bone area (BA, \%): percentage of the area inside a thread occupied by bone.

Statistical methods:

The statistical analyses were performed with the SPSS software (IBM, Armonk, USA).

Student t-test was used to compare the surface data obtained with the interferometer, in order to examine the difference in surface characteristics produced with the magnesium-loading. With the same purpose, results obtained with atomic force microscopy were compared using MannWhitney, a non-parametric test, due to the reduced number of measurements ( 9 per magnification per type of sample).

Wilcoxon signed-rank test was used to compare the removal torque and histomorphometrical values. This test compare the mean of the ranks of the data in the two groups and it was chosen due to the reduced number of samples, which does not allow a robust assessment of the normality of the distribution of the values. In addition, with this test it could be possible to consider the samples in the same animal as related.

For both tests the two-tails level of significance was placed $p \leq 0.05$. 


\section{RESULTS}

\section{Surface characterization}

\section{Interferometer}

The results are summarized in Table 1 and Figure 1 . They showed that the implant surfaces are rather smooth, with average $S_{a}$ value of $0.2 \mu \mathrm{m}$ for both test and control surfaces and average $S_{\mathrm{dr}}$ values of $13.9 \%$ and $9.0 \%$ for the test and the control samples respectively. The positive average values of $S_{\mathrm{sk}}$ described surfaces with on average more peaks than pits at a microscopic level. The difference in mean of the surface parameters for test and control samples was compared statistically (Student t-test), to detect if the magnesium treatment affected the topography. No significant differences were found for any of the parameters, although a tendency for the test surface to have a greater surface area was noticed.

\section{Atomic Force Microcopy}

The reconstructed images are displayed in Figure 2 and the numerical parameters are shown in Table 23. On both test and the control surfaces the nanostructures appeared to be homogenously distributed. The statistical comparison of the test and control samples served to evaluate the influence of the magnesium adsorption on the nanoroughness. A significant difference was observed between the test and the control surface especially on the smaller scan areas, suggesting that the chemical modification of the surfaces with magnesium changed the nanotopography.

\section{Scanning electron microscopy}

The images obtained are shown in Figure 3. The SEM micrographs displayed a homogenous topography of the surface, with evenly distributed pores with an average pore size of $6 \mathrm{~nm}$. The thickness of the mesoporous layers was measured in a scratched area (Fig 4) and it demonstrated a film thickness of $200 \mathrm{~nm}$. The appearance of the mesoporous surfaces reflected what has previously been described ${ }^{12}$. 
Energy dispersive spectroscopy.

The spectra of the elements detected on the surfaces are presented as atomic $\%$ in Table 3 . The examination confirmed the loading of $\mathrm{Mg}$ onto the titanium surface, while the element was not present in the native mesoporous layers. Both the surfaces consisted of Ti and O.

\section{In vivo experimentation}

No animals died during the surgery or in the post-operative period and all the animals healed uneventfully. No disabilities in motion were noticed and no infection or flap dehiscence was observed. At the time of dissection, all the implants were in place and no signs of fibrous integration (mobility, lack of stability) or infection were detected. The implants appeared osseointegrated and were well-positioned in the tibiae, surrounded by a restored cortical bone, with no signs of periosteal reaction.

\section{Removal torque test}

The values of the removal torque analysis are displayed in Fig. 5. The mean RTQ values were $21.9( \pm 11.2) \mathrm{Ncm}$ for the control group and $34.6( \pm 12.9) \mathrm{Ncm}$ for the test group and the difference between the two was statistically significant $(p=0.012)$.

\section{Histological results}

Rapresentative histological pictures of one test and one control implants are shown in figure 6.

New bone apposition was observed around all the implants. The newly formed bone tissue, which filled the space between the osteotomy lines, still visible, and the implant surface, showed a high amount of osteocyte lacunae and osteons. Both periosteal and endosteal reactions were 
observable on most of the implants. The implants were engaged in the bone mostly in the its coronal half, while the lower threads were within the medullar canal.

The mean $( \pm \mathrm{SD})$ BIC, measured in the three best threads for each implants, was $8.5 \%$ $( \pm 3.4)$ and $15.2 \%( \pm 7.6)$ for the control and the test group, respectively. The BA was on average $74.4 \%( \pm 5.2)$ for the control implants and $66.6 \%( \pm 10.3)$ for the test implants. The mean percentage of BIC for the test group was almost double than the control. However, the Wilcoxon signed rank test for related samples did not show a statistical significance between control and test groups neither for BIC nor for BA values ( $p$-values 0.2 and 0.3 respectively).

\section{DISCUSSION}

In the present study, the peri-implant bone response to implant surfaces coated with a mesoporous titania layer with and without magnesium loading was evaluated. The results after 3 weeks in vivo showed that the addition of $\mathrm{Mg}$ on the surfaces significantly enhanced the early osseointegration of implants as observed in the biomechanical removal torque testing. The obtained results confirmed those of the previous studies, which proposed the use of $\mathrm{Mg}$ as a bioactive element on implant surfaces to influence and accelerate the osseointegration. Sul et al. tested the biomechanical strength of Mg-incorporated implants with different atomic concentrations in several studies in the rabbit tibia ${ }^{15,39,43,44}$. In one study, they evaluated the effects of Mg-doped surfaces, comparing them to turned implants, and found that the interfacial strength presented dose dependency and the most favorable composition was around 9 atomic percent $\mathrm{Mg}^{15}$. Similar results were obtained by Cho et al., who investigated the differences in peri-implant bone healing around blasted implants with various atomic concentrations of $\mathrm{Mg}$ and compared the biologic outcome with that of grit blasted implants without $\mathrm{Mg}$ (control) ${ }^{45}$. After 6 weeks of implantation in the rabbit tibia, the highest and statistically significant different values of reverse torque measurements where obtained by the implants with 9 atomic percent $\mathrm{Mg}$ on the surface. Of great interest was that the amount of $\mathrm{Mg}$ adsorbed on samples treated with the physical adsorption in the current study was 8 
atomic percent $\mathrm{Mg}$, as demonstrated in an in vitro study applying the same surface preparation ${ }^{46}$, which corresponded to the above-discussed previous investigations ${ }^{15,45}$.

Sul and colleagues utilized the term "biomechanical bonding" to described the stronger interface between the thicker oxide layer of $\mathrm{Mg}$ and the bone, although it is still difficult to discriminate the role of the surface chemistry and that of the surface topography in the bone healing. In the in vivo study by Kang and colleagues ${ }^{47}$ a superior behavior of Mg-incorporated implants was not observed, while, on the contrary, laser-etched implants showed a higher interfacial strength and bone-to-implant contact. However, the surface roughness of the laser-treated implants was significantly higher than those of the Mg-treated implants, which had also a significantly smaller developed area. The biomechanical interlocking with the highly porous and rough surface may be the reason why the rougher implants outperformed the Mg-incorporated smooth implants in that study and a positive effect of the biochemical bonding could not be observed.

In the current investigation, $\mathrm{Mg}$ was added onto smooth surfaces $\left(\mathrm{S}_{\mathrm{a}} 0.2 \mu \mathrm{m}\right.$ and $\left.\mathrm{S}_{\mathrm{dr}} 9-13 \%\right)$ and apparently, did not affect the surface roughness on the microscopic level, as shown by the similarity of interferometer data between the test and the control samples. The only value that showed an increasing trend for test surfaces was the $S_{\mathrm{dr}}$. This could be attributed to the difference in oxide thickness, which is a commonly observed on Mg-doped surface due to the calcination process, which is in accordance with previous reports ${ }^{48}$. Thus, it can be suggested that the addition of $\mathrm{Mg}$ did not alter significantly the topography at the micrometer level. SEM confirmed this finding, where the test and the control surfaces could not be distinguished apart at any magnification.

Of particular interest of the surface architecture used in the current study is that it combines an ordered nano-pattern and the possibility to incorporate bioactive elements, which can spur osteoconduction. The nanotopography was studied on both surface modifications with atomic force microscopy and SEM. A significant difference in roughness at the nanoscopic level was observed after the addition of $\mathrm{Mg}$. However the $\mathrm{Mg}$ on the top of the surfaces was expected to be release very 
rapidly, diversely than the $\mathrm{Mg}$ adsorbed into the porous network, that is administrated with a sustained release profile. Due to this behavior the attached $\mathrm{Mg}$ at the top of the surface and the consequent difference in nano-topography has probably been transient and has had a negligible effect.

It was demonstrated that the Mg-loaded surfaces required significantly higher removal torque to be detached from the bone. Reportedly, in the presence of chemically modified surfaces such as with $\mathrm{Mg}$, the bonding failure during removal torque testing occurred more within the bone than at the bone-implant interface ${ }^{43}$. This is an indication that the chemical effect of the $\mathrm{Mg}$ improved the bone mineralization properties, which may strengthen the bone quality.

Moreover, the removal torque values were high also for the control implants (mean values of $21 \mathrm{Ncm})$. In a recent in vivo study, Jimbo et al. ${ }^{6}$ demonstrated that the presence of nanostructures on implant surfaces significantly strengthened the bone mechanical properties in proximity to the implant. A significant influence of nanostructures on bone response was shown also in a recent report from Wennerberg et al. ${ }^{49}$. The authors assessed the degree of biomechanical bonding of surfaces with similar chemistry and microtopography, but different nanotopography and wettability. They observed that the nanotopography had significant influence on the interfacial strength. Hence, the biologic outcome of the current study was a combination of nanostructure of the base substrate, which was further improved with the chemical effects of $\mathrm{Mg}$.

The corresponding histologic evaluation suggested that for both control and test surfaces, the bone healing around the implants after 3 weeks in vivo, presented no signs of major inflammation or the localization of multinucleated giant cells, which may have lead to bone resorption. In general, bone around both surfaces presented an immature woven bone structure and newly formed bone was in close contact to the implant especially in the cortical region. Although the number of samples utilized for the histology was restricted to 4 , the mean histomorphomteric values presented that the mean values were higher for the Mg-loaded mesoporous implants. Due to the low number of samples, the statistical conclusions cannot be considered robust, however, the 
mean values presented are in accordance with the biomechanical outcomes. Thus, it can be speculated that the high removal torque values obtained for the Mg-loaded surfaces is a result of improved bone quality around the implant and more bone attachment to the implant.

Mesoporous is defined as a material having a pore size between 2 and $50 \mathrm{~nm}^{50}$. This ordered structure is derived from self-assembly of a structure directing agent and an inorganic precursor. The various parameters of the reaction $(\mathrm{pH}$, temperature and solvent) and the template/inorganic ratio determine the aggregation structure. In the current study, the reaction parameters and the concentration of reagents were chosen to have a cubic structure, to make sure that pores $(6 \mathrm{~nm}$ in diameter) are facing out from the surface ${ }^{12}$. Thereby, the incorporated substances can be subsequently released to the surrounding bone tissue. The high pore volume and the high specific surface area of the mesoporous matrix enable the required amount for therapeutic affect of chemical $(\mathrm{Mg})$ to be hosted.

However, the release rate of $\mathrm{Mg}$ could be a factor to consider for further improvements. Mesoporous materials possess features that can tune the release behavior of the active substance, for future studies it would be of interest to optimize the release of $\mathrm{Mg}$ from the surface to determine how the biologic effect of $\mathrm{Mg}$ incorporation could be maximized.

\section{CONCLUSIONS}

In the current study, titanium implants with a mesoporous surface, where Magnesium had been incorporated, show stronger interaction with bone than compared to its control, coated with mesoporous and titania without magnesium, after 3 weeks of healing in rabbit. The RTQ values were statistically significantly higher for the test samples, which are with Mg-loading. The implants were characterized morphologically, topographically and chemically before placement, showing a comparable roughness, a homogenous distribution of nanopores with $6 \mathrm{~nm}$ in diameter, the only difference between the test and control group was the presence of magnesium on the test surfaces. 
The histological evaluation displayed bone formation around all surfaces. Moreover, a tendency of a higher bone-to-implant contact for the Mg-loaded surfaces was observed.

The performed in vivo study concluded that a local release of magnesium from the implant surfaces enhance the osseointegration at the early stage of the healing ( 3 weeks), which is highly desirable for early loading of the implant.

\section{ACKNOWLEDGMENT}

Silvia Galli is part of the MagnIM Marie Curie Initial Training Network, which receives funding from the People Program (Marie Curie Actions) of the European Union's Seventh Framework Program FP7 (2007-2013) under REA Grant Agreement No 289163.

Johan Karlsson and Martin Andersson thank the Materials Area of Advance at Chalmers University of Technology for financial support.

None of the authors have any conflict interest to report. 


\section{REFERENCES}

1. Davies JE. Understanding peri-implant endosseous healing. J Dent Educ 2003; 67: 932949.

2. Elias CN, Oshida Y, Lima JH, Muller CA. Relationship between surface properties (roughness, wettability and morphology) of titanium and dental implant removal torque.J Mech Behav Biomed Mater 2008; 1: 234-242.

3. Albrektsson T, Wennerberg A. Oral implant surfaces: Part 1--review focusing on topographic and chemical properties of different surfaces and in vivo responses to them. Int J Prosthodont 2004; 17: 536-543.

4. Albrektsson T, Johansson C. Osteoinduction, osteoconduction and osseointegration. Eur Spine J 2001; 10 Suppl 2: S96-101.

5. Frojd V, Franke-Stenport V, Meirelles L, Wennerberg A. Increased bone contact to a calcium-incorporated oxidized commercially pure titanium implant: an in-vivo study in rabbits. Int J Oral Maxillofac Surg 2008; 37: 561-566.

6. Jimbo R, Coelho PG, Bryington M, et al. Nano hydroxyapatite-coated implants improve bone nanomechanical properties. J Dent Res 2012; 91: 1172-1177.

7. Avila G, Misch K, Galindo-Moreno P, Wang HL. Implant surface treatment using biomimetic agents. Implant Dent 2009; 18: 17-26.

8. Wennerberg A, Jimbo R, Albrektsson T. On current knowledge of nano surfaces and their use in oral implantology. Implant News 2012; 9: 483-491.

9. Webster TJ, Ahn ES. Nanostructured biomaterials for tissue engineering bone. Adv Biochem Eng Biotechnol 2007; 103: 275-308.

10. Wennerberg A, Albrektsson T. Structural influence from calcium phosphate coatings and its possible effect on enhanced bone integration. Acta Odontologica Scandinavica 2009; 67: 333-340.

11. Jimbo R, Sotres J, Johansson C, Breding K, Currie F, Wennerberg A. The biological response to three different nanostructures applied on smooth implant surfaces. Clin Oral Implants Res 2012; 23: 706-712.

12. Karlsson J, Jimbo R, Fathali HM, et al. In vivo biomechanical stability of osseointegrating mesoporous TiO(2) implants. Acta Biomater 2012; 8: 4438-4446.

13. Harmankaya N, Karlsson J, Palmquist A, et al. Raloxifene and alendronate containing thin mesoporous titanium oxide films improve implant fixation to bone. Acta Biomater 2013; 9: 7064-7073.

14. Jimbo R, Sawase T, Baba K, Kurogi T, Shibata Y, Atsuta M. Enhanced Initial Cell Responses to Chemically Modified Anodized Titanium. Clinical Implant Dentistry and Related Research 2008; 10: 55-61.

15. Sul YT, Johansson C, Wennerberg A, Cho LR, Chang BS, Albrektsson T. Optimum surface properties of oxidized implants for reinforcement of osseointegration: surface chemistry, oxide thickness, porosity, roughness, and crystal structure. Int J Oral Maxillofac Implants 2005; 20: 349-359.

16. Ellingsen JE, Johansson CB, Wennerberg A, Holmen A. Improved retention and bonetolmplant contact with fluoride-modified titanium implants. Int J Oral Maxillofac Implants 2004; 19: 659-666.

17. Sawase T, Wennerberg A, Baba K, et al. Application of oxygen ion implantation to titanium surfaces: effects on surface characteristics, corrosion resistance, and bone response. Clin Implant Dent Relat Res 2001; 3: 221-229. 
18. Bucci-Sabattini V, Cassinelli C, Coelho PG, Minnici A, Trani A, Dohan Ehrenfest DM. Effect of titanium implant surface nanoroughness and calcium phosphate low impregnation on bone cell activity in vitro. Oral Surg Oral Med Oral Pathol Oral Radiol Endod 2010; 109: 217-224.

19. Jimbo R, Xue Y, Hayashi M, et al. Genetic responses to nanostructured calciumphosphate-coated implants. J Dent Res 2011; 90: 1422-1427.

20. Quaranta A, Iezzi G, Scarano A, et al. A histomorphometric study of nanothickness and plasma-sprayed calcium-phosphorous-coated implant surfaces in rabbit bone.J Periodontol 2010; 81: 556-561.

21. Wennerberg A, Jimbo R, Allard S, Skarnemark G, Andersson M. In vivo stability of hydroxyapatite nanoparticles coated on titanium implant surfaces. Int J Oral Maxillofac Implants 2011; 26: 1161-1166.

22. Sul YT, Kang BS, Johansson C, Um HS, Park CJ, Albrektsson T. The roles of surface chemistry and topography in the strength and rate of osseointegration of titanium implants in bone. J Biomed Mater Res A 2009; 89: 942-950.

23. Sul YT, Kwon DH, Kang BS, Oh SJ, Johansson C. Experimental evidence for interfacial biochemical bonding in osseointegrated titanium implants. Clin Oral Implants Res 2013; 24

Suppl A100: 8-19.

24. Ko YH, Hong S, Pedersen PL. Chemical mechanism of ATP synthase. Magnesium plays a pivotal role in formation of the transition state where ATP is synthesized from ADP and inorganic phosphate. J Biol Chem 1999; 274: 28853-28856.

25. Leidi M, Dellera F, Mariotti M, et al. Nitric oxide mediates low magnesium inhibition of osteoblast-like cell proliferation. J Nutr Biochem 2012; 23: 1224-1229.

26. Abed E, Moreau R. Importance of melastatin-like transient receptor potential 7 and cations (magnesium, calcium) in human osteoblast-like cell proliferation. Cell Prolif 2007; 40: 849-865.

27. Abed E, Moreau R. Importance of melastatin-like transient receptor potential 7 and magnesium in the stimulation of osteoblast proliferation and migration by platelet-derived growth factor. Am J Physiol Cell Physiol 2009; 297: C360-368.

28. Nguyen TY, Garcia S, Liew CG, Liu H. Effects of magnesium on growth and proliferation of human embryonic stem cells. Conf Proc IEEE Eng Med Biol Soc 2012; 2012: 723-726.

29. Rude RK, Kirchen ME, Gruber HE, Meyer MH, Luck JS, Crawford DL. Magnesium deficiency-induced osteoporosis in the rat: uncoupling of bone formation and bone resorption. Magnes Res 1999; 12: 257-267.

30. Stendig-Lindberg G, Koeller W, Bauer A, Rob PM. Prolonged magnesium deficiency causes osteoporosis in the rat. J Am Coll Nutr 2004; 23: 704S-711S.

31. Park JW, Kim YJ, Jang JH, Song H. Osteoblast response to magnesium ion-incorporated nanoporous titanium oxide surfaces. Clin Oral Implants Res 2010; 21: 1278-1287.

32. Salimi MH, Heughebaert JC, Nancollas GH. Crystal growth of calcium phosphates in the presence of magnesium ions. Langmuir 1985; 1: 119-122.

33. Zreiqat H, Howlett CR, Zannettino A, et al. Mechanisms of magnesium-stimulated adhesion of osteoblastic cells to commonly used orthopaedic implants. J Biomed Mater Res 2002; 62: 175-184.

34. Zreiqat $\mathrm{H}$, Valenzuela SM, Nissan BB, et al. The effect of surface chemistry modification of titanium alloy on signalling pathways in human osteoblasts. Biomaterials 2005; 26: 75797586.

35. Cai Y, Zhang S, Zeng X, Wang Y, Qian M, Weng W. Improvement of bioactivity with magnesium and fluorine ions incorporated hydroxyapatite coatings via sol-gel deposition on Ti6Al4V alloys. Thin Solid Films 2009; 517: 5347-5351. 
36. Castellani C, Lindtner RA, Hausbrandt P, et al. Bone-implant interface strength and osseointegration: Biodegradable magnesium alloy versus standard titanium control. Acta Biomater 2011; 7: 432-440.

37. Park JW, An CH, Jeong SH, Suh JY. Osseointegration of commercial microstructured titanium implants incorporating magnesium: a histomorphometric study in rabbit cancellous bone. Clin Oral Implants Res 2012; 23: 294-300.

38. Alenezi A, Naito Y, Andersson M, Chrcanovic BR, Wennerberg A, Jimbo R. Characteristics of 2 Different Commercially Available Implants with or without Nanotopography. Int J Dent 2013; 2013: 769768.

39. Sul YT, Johansson C, Albrektsson T. Which surface properties enhance bone response to implants? Comparison of oxidized magnesium, TiUnite, and Osseotite implant surfaces. Int J Prosthodont 2006; 19: 319-328.

40. Alberius PCA, Frindell KL, Hayward RC, Kramer EJ, Stucky GD, Chmelka BF. General Predictive Syntheses of Cubic, Hexagonal, and Lamellar Silica and Titania Mesostructured Thin Films§. Chemistry of Materials 2002; 14: 3284-3294.

41. Wennerberg A, Albrektsson T. Suggested guidelines for the topographic evaluation of implant surfaces. Int J Oral Maxillofac Implants 2000; 15: 331-344.

42. Donath K. Preparation of Histologica Sections by the Cutting-Grinding Technique for Hard Tissue and other Material not suitable to be sectioned by routine methods. EXAKTKulzer, Norderstedt 1993: 1:16.

43. Sul YT, Johansson C, Byon E, Albrektsson T. The bone response of oxidized bioactive and non-bioactive titanium implants. Biomaterials 2005; 26: 6720-6730.

44. Sul YT, Johansson P, Chang BS, Byon ES, Jeong Y. Bone tissue responses to Mgincorporated oxidized implants and machine-turned implantsin the rabbit femur. J Appl Biomater Biomech 2005; 3: 18-28.

45. Cho LR, Kim DG, Kim JH, Byon ES, Jeong YS, Park CJ. Bone response of Mg ion-implanted clinical implants with the plasma source ion implantation method. Clin Oral Implants Res 2010; 21: 848-856.

46. Cecchinato F, Xue Y, Karlsson J, et al. In vitro evaluation of human fetal osteoblast response to magnesium loaded mesoporous TiO coating. J Biomed Mater Res A 2013.

47. Kang SH, Cho JH, Park SH, Toothaker R, Cho SA. Comparison of osseointegration between laser-etched and magnesium-incorporated oxidized implants in the rabbit femur. Int J Oral Maxillofac Implants 2013; 28: 775-781.

48. Sul YT, Jeong Y, Johansson C, Albrektsson T. Oxidized, bioactive implants are rapidly and strongly integrated in bone. Part 1--experimental implants. Clin Oral Implants Res 2006; 17: 521-526.

49. Wennerberg A, Jimbo R, Stubinger S, Obrecht M, Dard M, Berner S. Nanostructures and hydrophilicity influence osseointegration: a biomechanical study in the rabbit tibia. Clin Oral Implants Res 2013: n/a-n/a.

50. McCusker LB, Liebau F, Engelhardt G. Nomenclature of structural and compositional characteristics of ordered microporous and mesoporous materials with inorganic hosts(IUPAC Recommendations 2001). Pure and Applied Chemistry 2001; 73: 381-394. 

Table 1. Topographical analyses made with interferometer (average \pm standard deviation). The surface parameters used are $S_{a}$, the arithmetical mean roughness, $S_{d r}$, the developed surface area ratio, and $S_{d s}$, the density of the summits in the sampling area

\begin{tabular}{|l|l|l|l|l|}
\hline & $\mathbf{S}_{\mathbf{a}}(\boldsymbol{\mu m})$ & $\mathbf{S}_{\mathbf{d s}}\left(\mathbf{m m m}^{2)}\right.$ & $\mathbf{S}_{\text {sk }}$ & $\mathbf{S}_{\text {dr }}(\boldsymbol{\%})$ \\
\hline Control (mean \pm SD) & $0.25 \pm 0.09$ & $170297.74 \pm 43992.1$ & $3.05 \pm 9.58$ & $9.06 \pm 6.01$ \\
\hline Test (mean \pm SD) & $0.26 \pm 0.09$ & $162842.7 \pm 62664.0$ & $7.21 \pm 14.65$ & $13.89 \pm 11.91$ \\
\hline $\begin{array}{l}\text { p-value (Student-t } \\
\text { test) }\end{array}$ & 0.9 & 0.6 & 0.2 & 0.06 \\
\hline
\end{tabular}


Table 2. Topographical analyses using atomic force microscopy (average \pm standard deviation). $P$ values were obtained with Mann-Withney test.

\begin{tabular}{|c|c|c|c|c|c|c|c|c|c|}
\hline & \multicolumn{3}{|c|}{$10 \times 10 \mu \mathrm{m}$} & \multicolumn{3}{|c|}{$1 \mathrm{X} 1 \mu \mathrm{m}$} & \multicolumn{3}{|c|}{$500 \times 500 \mathrm{~nm}$} \\
\hline & Control & Test & $p$-value & Control & Test & $p$-value & Control & Test & $p$-value \\
\hline $\mathrm{S}_{\mathrm{a}}(\mathrm{nm})$ & $\begin{array}{l}16.31 \pm \\
2.9\end{array}$ & $\begin{array}{l}16.30 \pm \\
3\end{array}$ & 1 & $\begin{array}{l}1.13 \pm \\
0.6\end{array}$ & $\begin{array}{l}0.59 \pm \\
0.1\end{array}$ & $0.006^{*}$ & $\begin{array}{l}0.58 \pm \\
0.2\end{array}$ & $\begin{array}{l}0.31 \pm \\
0.09\end{array}$ & $0.004 *$ \\
\hline $\mathrm{S}_{\mathrm{dr}}(\%)$ & $\begin{array}{l}0.67 \pm \\
0,2\end{array}$ & $\begin{array}{l}0.42 \pm \\
0.2\end{array}$ & 0,063 & $\begin{array}{l}1.83 \pm \\
1.1\end{array}$ & $\begin{array}{l}0.48 \pm \\
0.2\end{array}$ & $0.001 *$ & $\begin{array}{l}3.28 \pm \\
2.3\end{array}$ & $\begin{array}{l}0.93 \pm \\
0.4\end{array}$ & $0.02 *$ \\
\hline $\begin{array}{l}\mathrm{S}_{\mathrm{ds}} \\
(1 / \mu \mathrm{m} 2)\end{array}$ & $\begin{array}{l}11.94 \pm \\
9.8 .4\end{array}$ & $\begin{array}{l}3.72 \pm \\
2.4\end{array}$ & $0,001 *$ & $\begin{array}{l}3456 \pm \\
931\end{array}$ & $\begin{array}{l}3380 \pm \\
1211\end{array}$ & 0.8 & $\begin{array}{l}10181 \\
\pm 2035\end{array}$ & $\begin{array}{l}10007 \\
\pm 3405\end{array}$ & 0.8 \\
\hline
\end{tabular}


Table 3.Chemical composition obtained using EDS on 3 different areas for each implant type (top, flank and valley). Values are expressed in atomic\%. MP: native mesoporous; MP-Mg: mesoporous loaded with $\mathrm{Mg}$ ions..

\begin{tabular}{|c|c|c|c|c|}
\hline & $\mathrm{C}$ & $\mathrm{O}$ & $\mathrm{Mg}$ & $\mathrm{Ti}$ \\
\hline MP top & 5.04 & 43.74 & 0 & 51.22 \\
\hline MP flank & 7.65 & 59.18 & 0 & 33.17 \\
\hline MP valley & 4.42 & 34.53 & 0 & 61.06 \\
\hline MP-Mg top & 9.96 & 50.84 & 0.52 & 38.68 \\
\hline MP-Mg flank & 6.11 & 55.46 & 0.78 & 37.66 \\
\hline MP-Mg valley & 5.09 & 45.45 & 1.64 & 47.82 \\
\hline
\end{tabular}




\section{FIGURE CAPTIONS:}

Figure 1.3D topographical images of the implant surfaces obtained with white light optical interferometer(scan area $200 \times 110 \mu \mathrm{m}$ ). The surfaces appear turned at a micrometer level.

Figure 2. Descriptive 3D images of the implants surfaces obtained with atomic force microscopy.

(a)(c) Native mesoporous coating. (b)(d) Mesoporous coating with Mg-ions. (a)(c). scan size 1 X 1. (b)(d) scan size 500 X $500 \mathrm{~nm}$. At scan size of 1 X $1 \mu \mathrm{m}$ and 500 X $500 \mathrm{~nm}$ a homogenously arranged nanostructure is visible.

Figure 3. Scanning electron microscopy images of the implant surfaces, where it is possible to visualize the mesopores of the titanium coating. The pores are approximately $6 \mathrm{~nm}$ in diameter. (a) Native mesoporous coating, magnification 230.000X (bar $100 \mathrm{~nm}$ ) (b) Mg-loaded mesoporous coating, magnification $230.000 \mathrm{X}$ (bar $100 \mathrm{~nm}$ ).

Figure . Scanning electron microscopy image of a scratch in the mesoporous coating. It is possible to observe the thickness of the coating, around $200 \mathrm{~nm}$, and the underlying surface of the titanium bulk (magnification 270.000X, bar $100 \mathrm{~nm}$ ).

Figure 5. Removal torque values for test and control implants. The test implants was found to have a stronger bone-to-implant interface, has revealed by the statistically significant higher force was required to loosen the screws from the bone. Statistical test used: Wiloxon signed rank, a nonparametric test for paired samples.

Figure 6. Histological sections of a test and a control implant observed using light microscopy. (a) Control implant observed at different magnification (20X and 40X). (b) Test implant observed at different magnifications (20X and 40X). Toluidine blue staining. Evidences of new bone formation 
within the threads of both implants and in close contact with the surfaces are shown. Osteocyte lacunae are visible.

\section{Figures:}

Fig.1

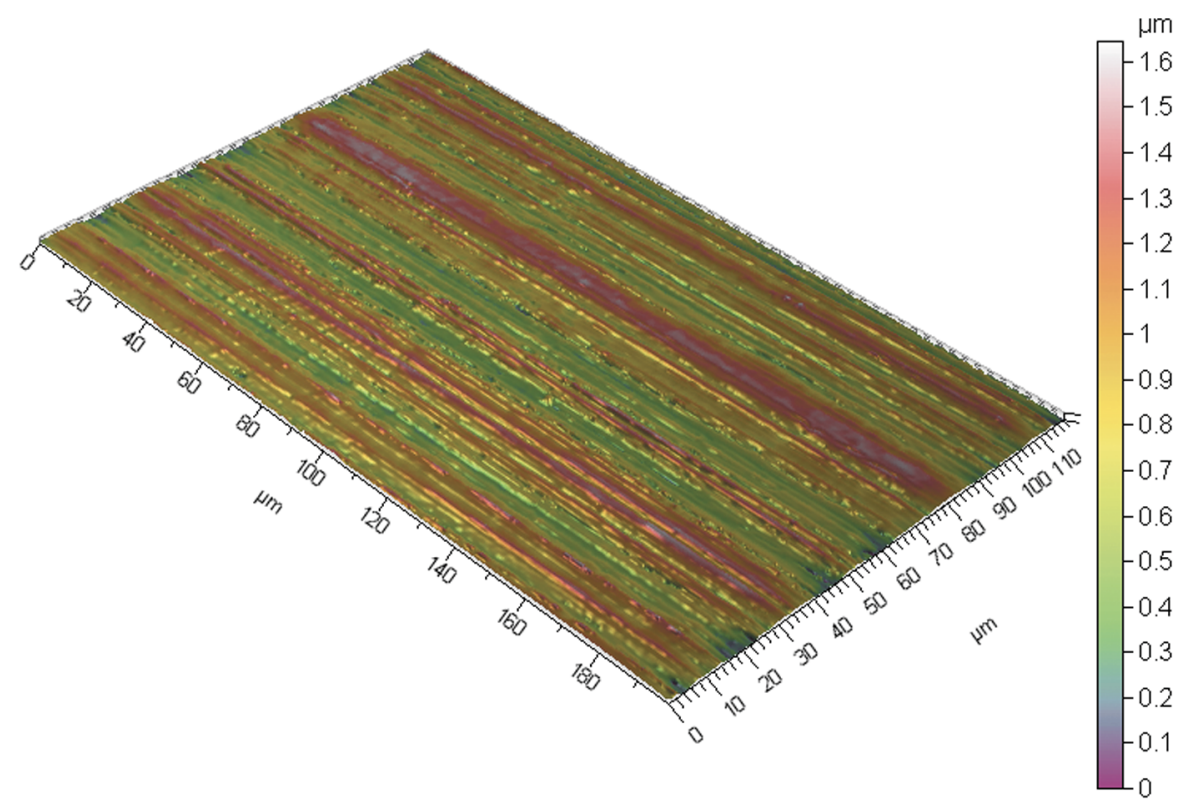

Fig. 2a

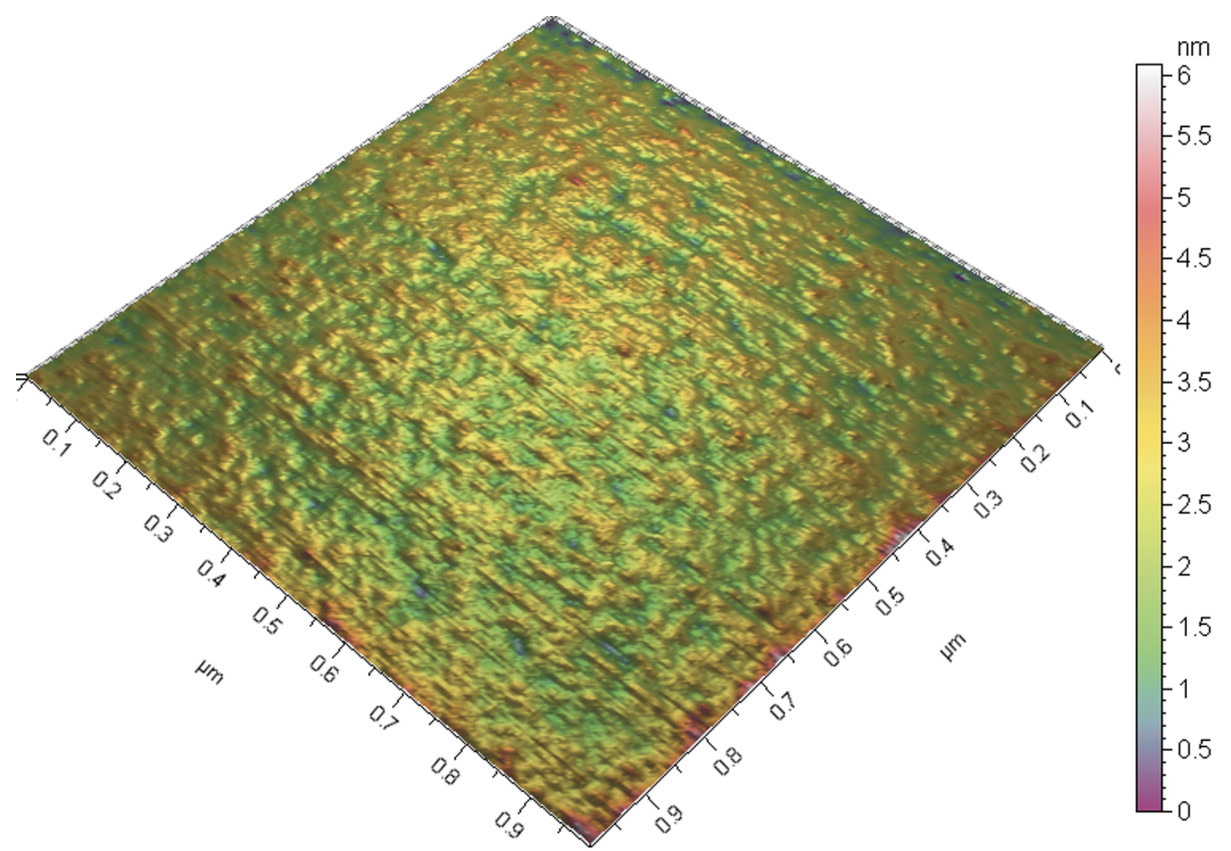


Fig 2b

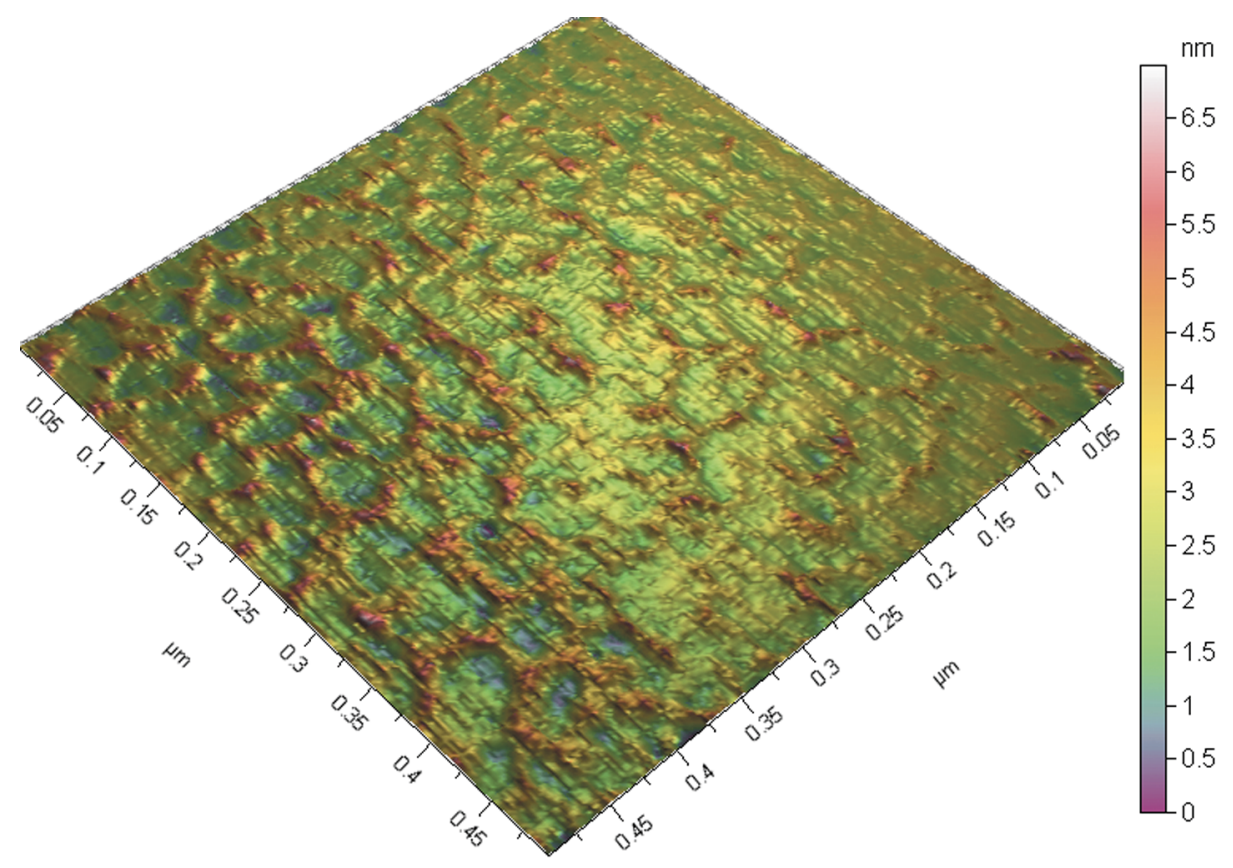

Fig. 2c

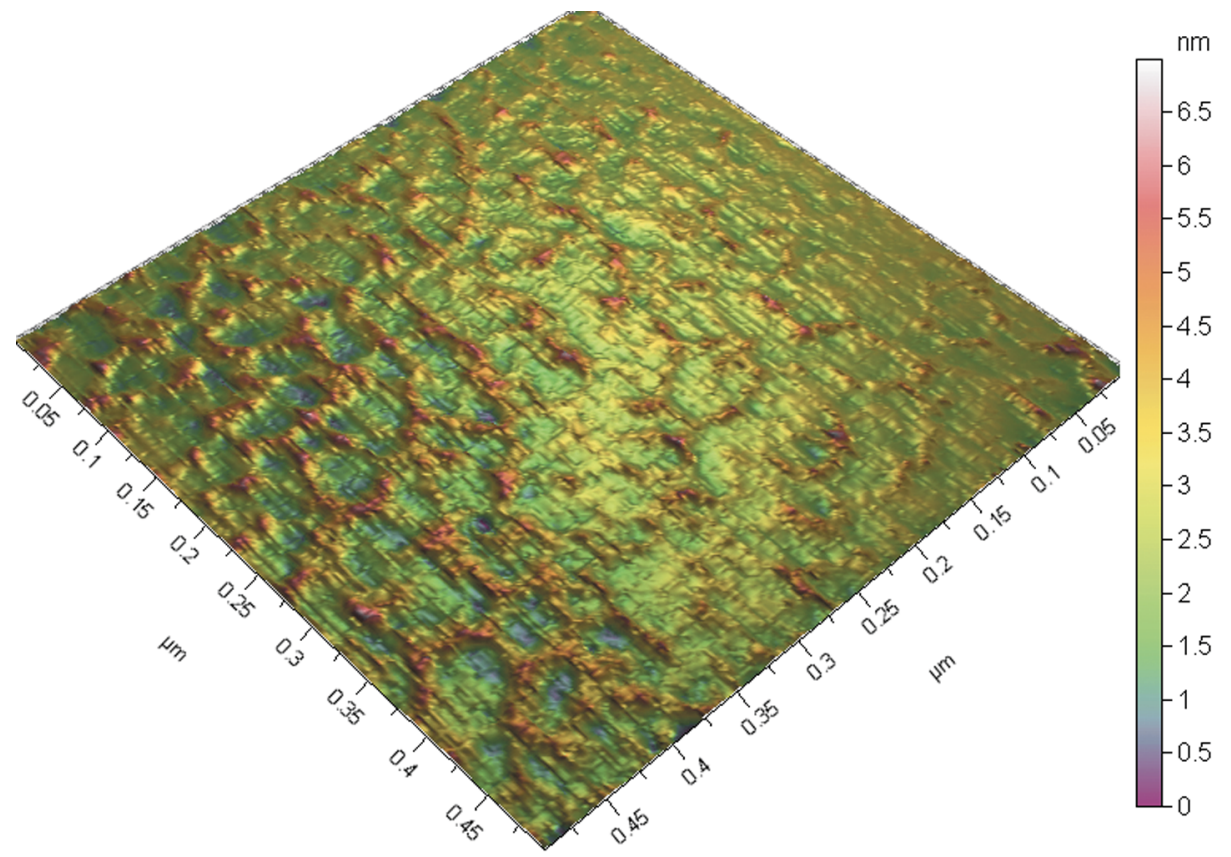

Fig.2d 


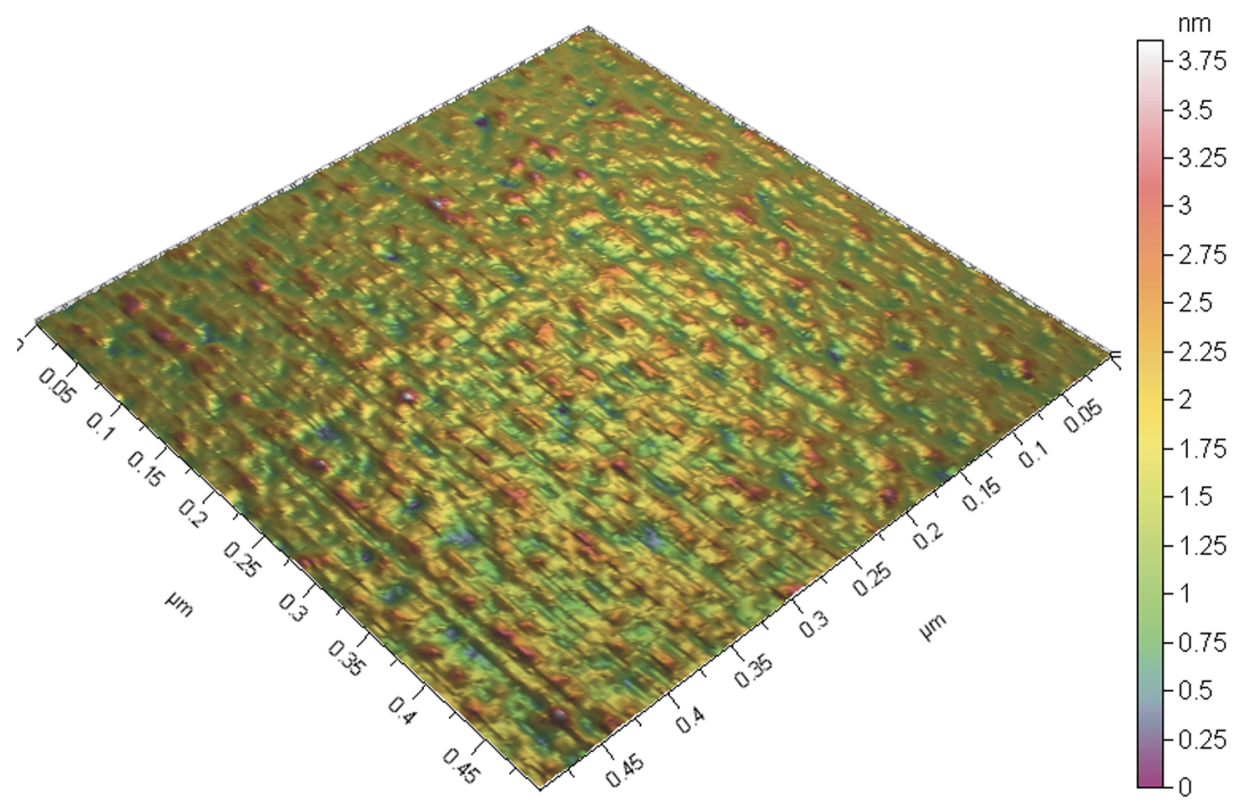

Fig.3a

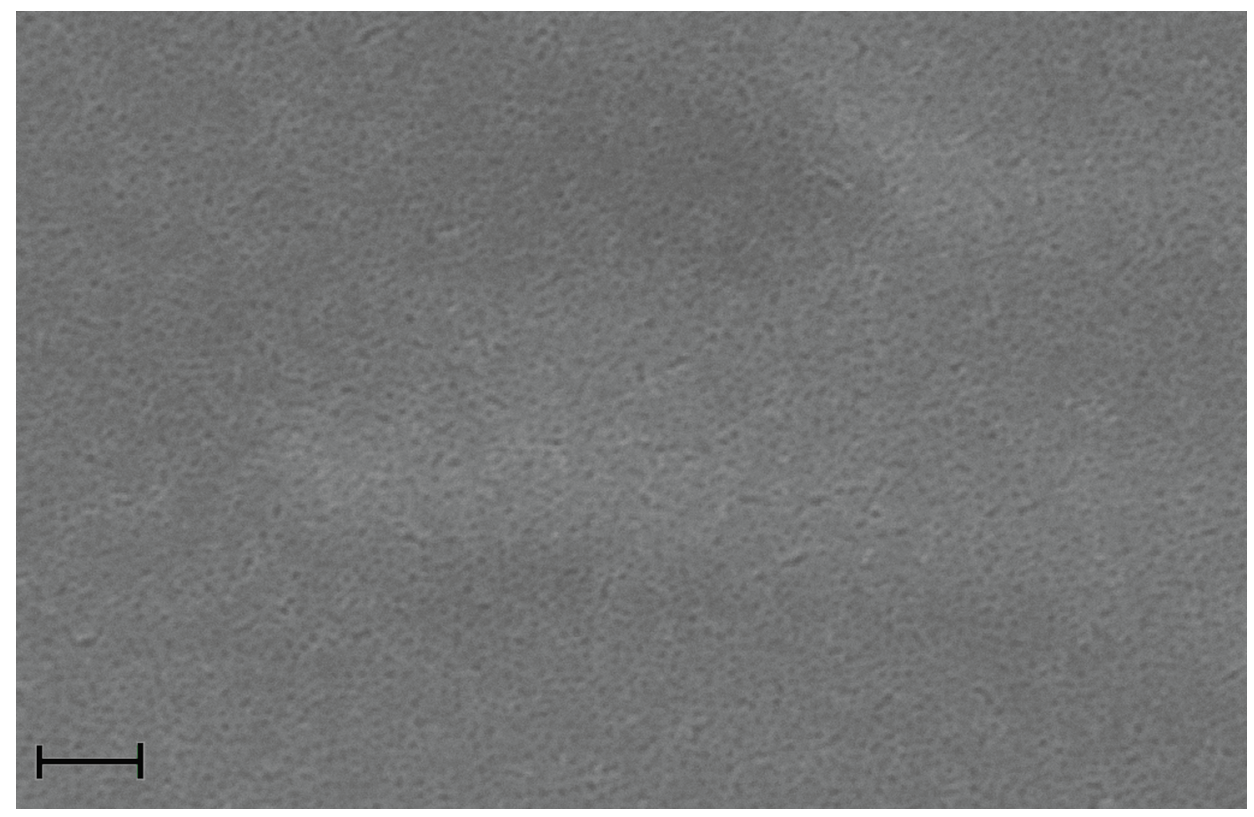

Fig.3b 


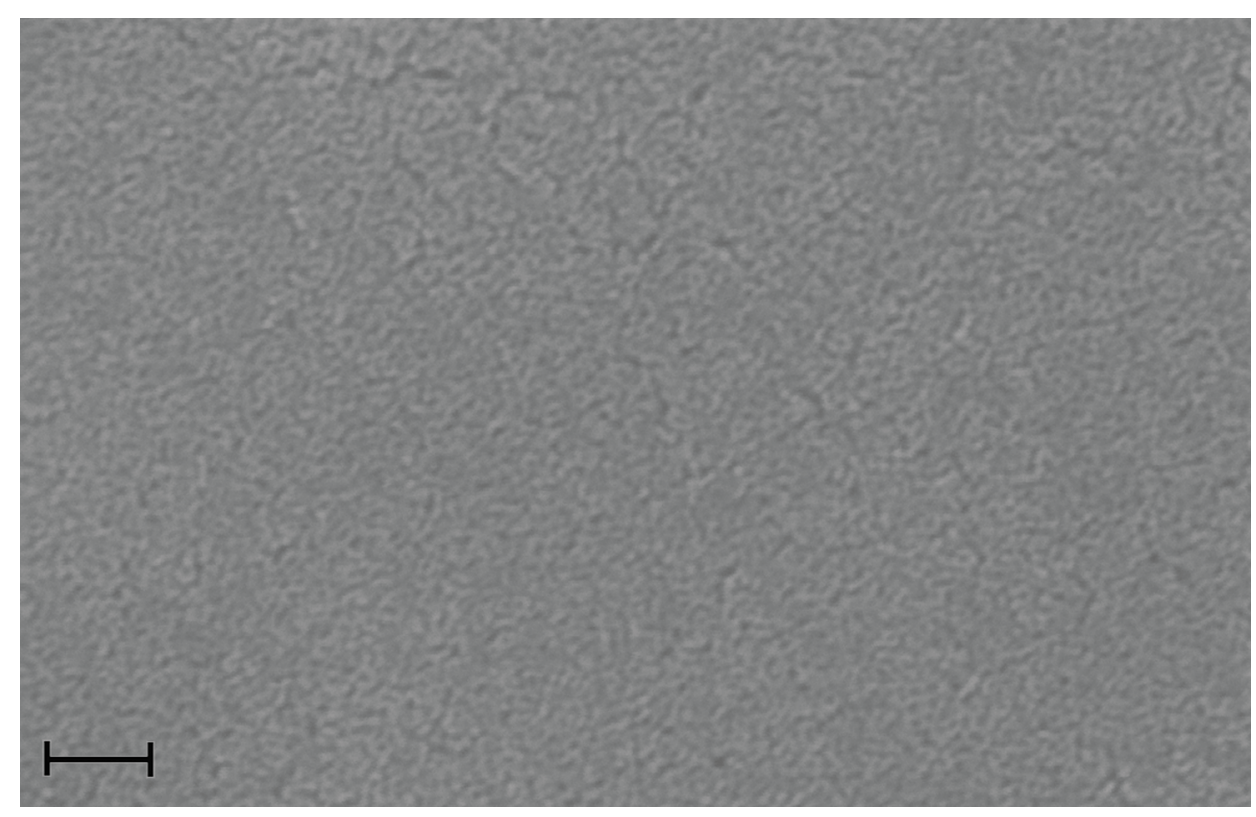

Fig 4

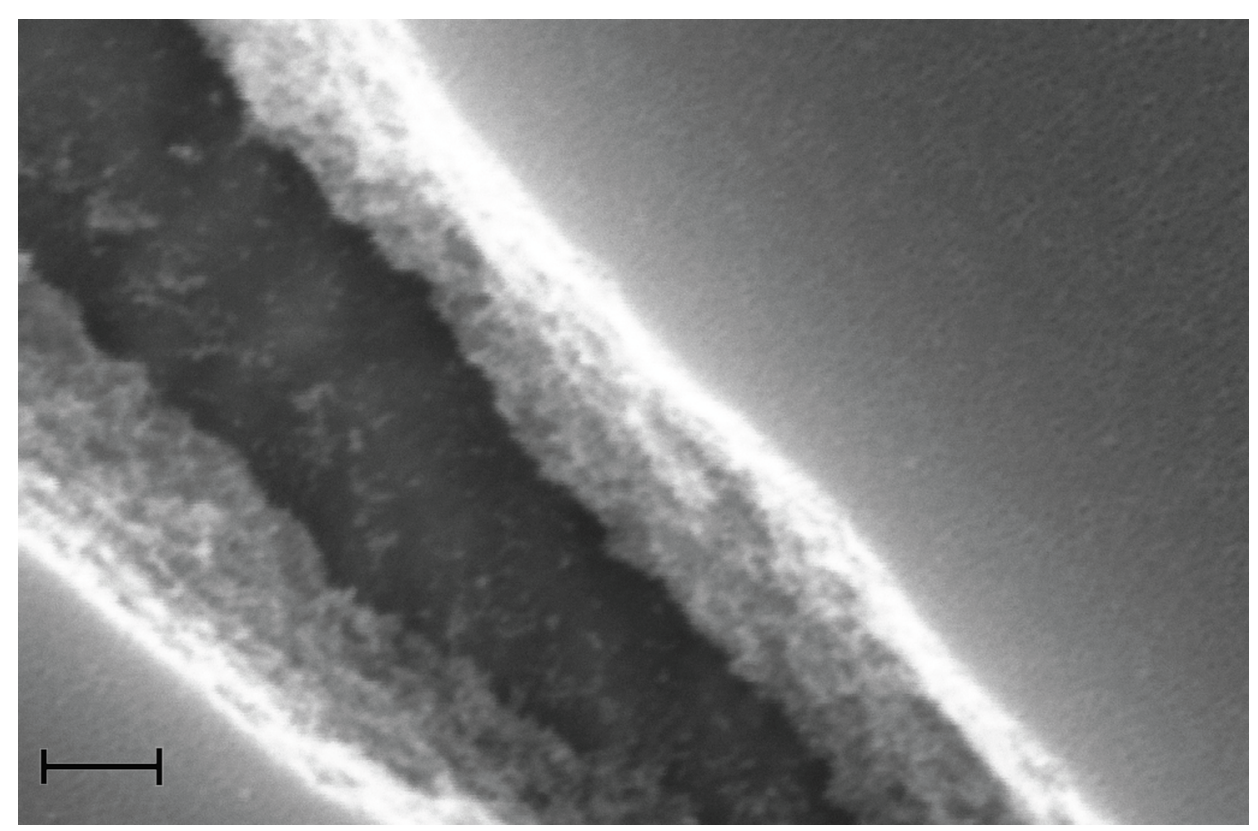

Fig.5 


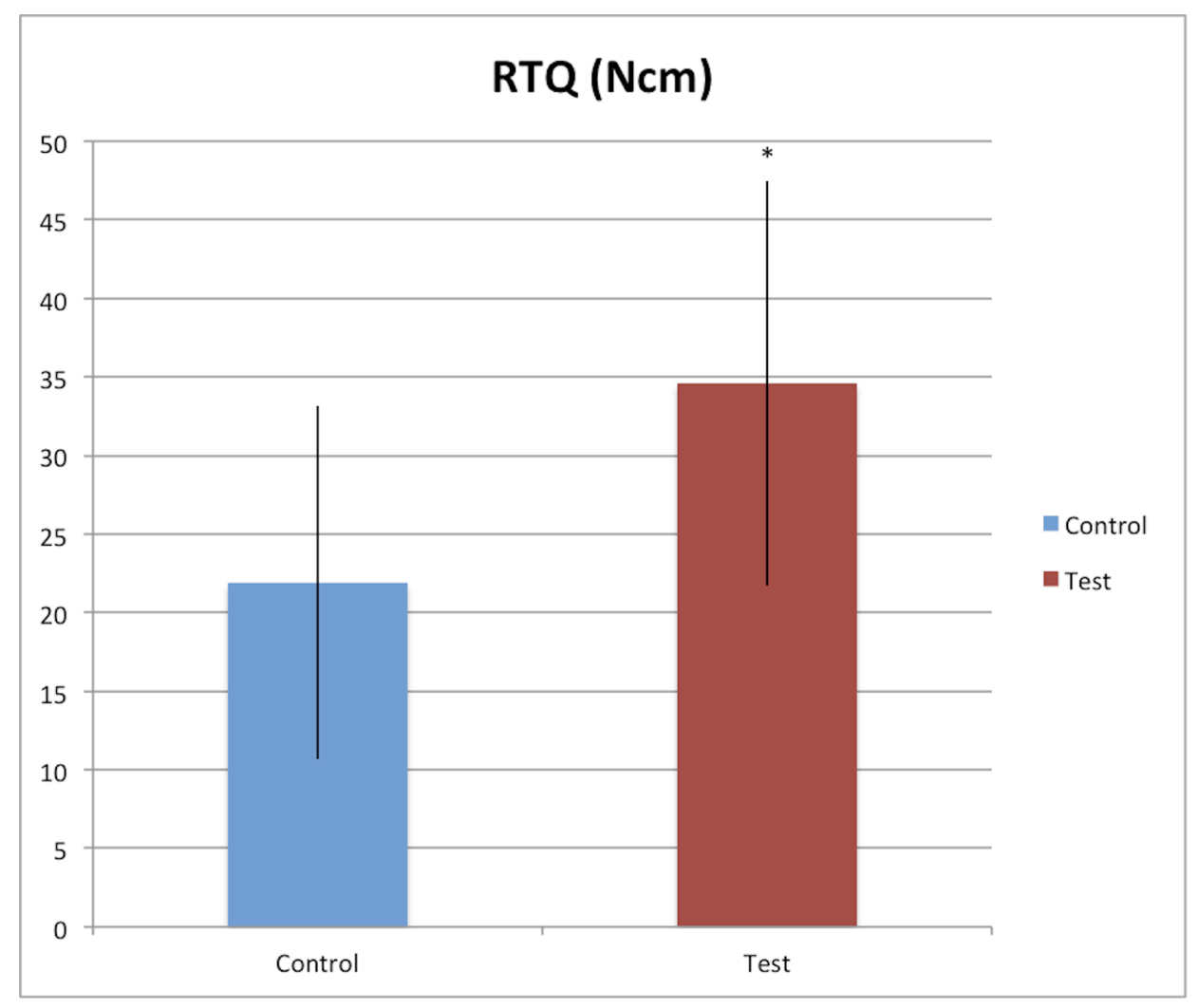

Fig. 6a

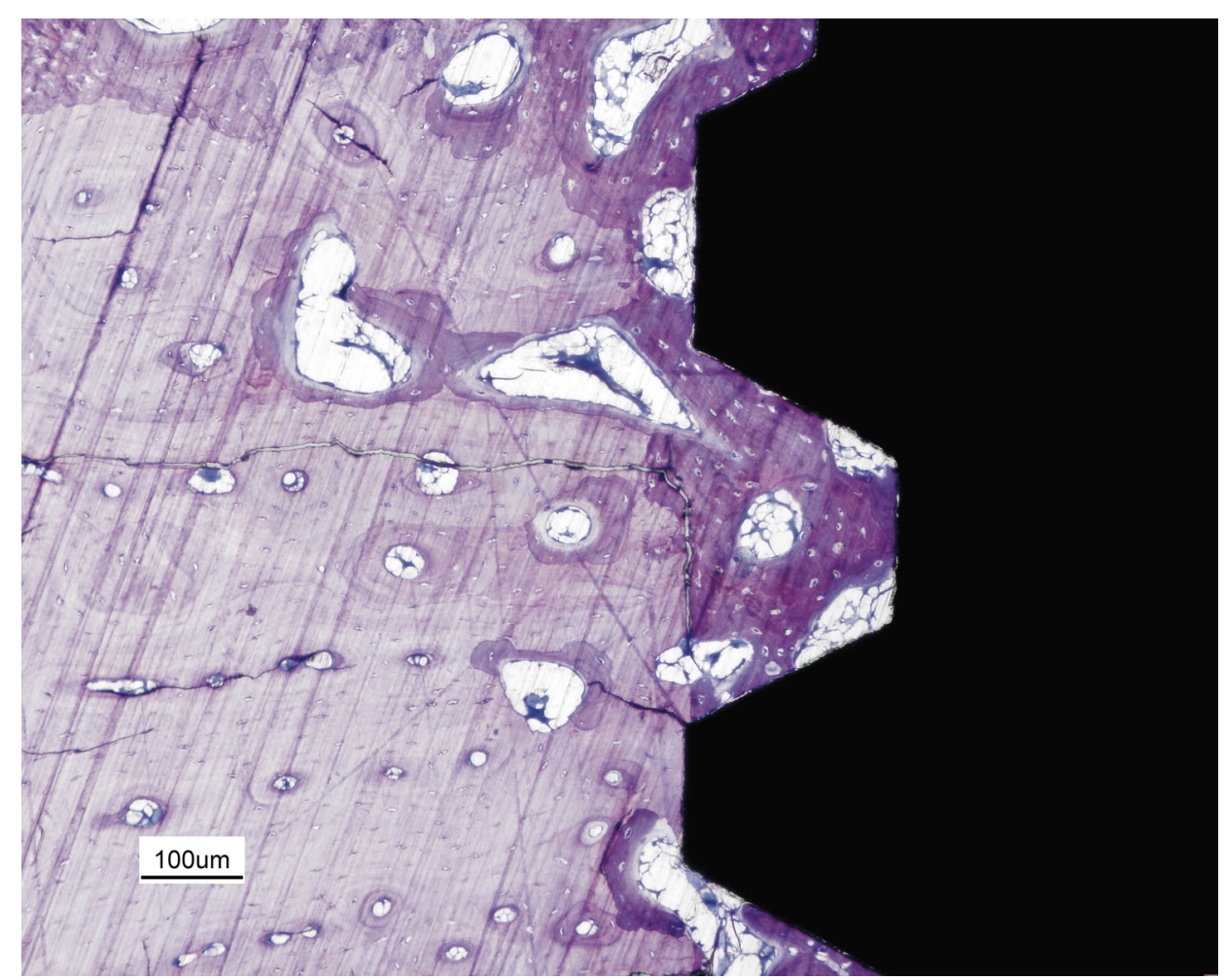


Fig. 6b

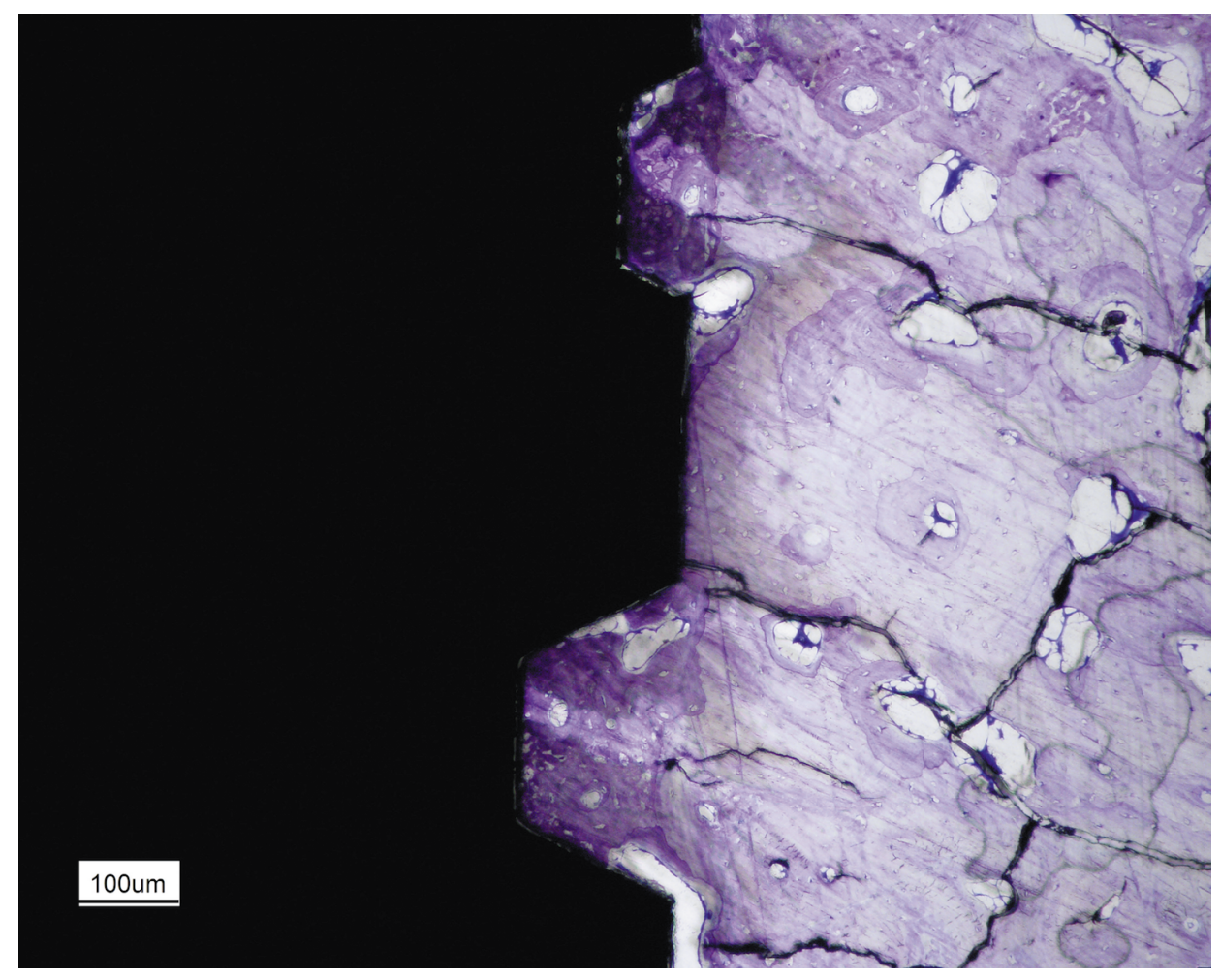

